\title{
Role of Anterior Segment OCT in the Management of Primary Narrow Angle Disease
}

\author{
Sadia Farooq ${ }^{1}$, Javeria Muid ${ }^{2}$ \\ 1-2 Ophthalmology Clinic, Shifa International Hospital H-8/4, Islamabad
}

\begin{abstract}
Purpose: To highlight the role of anterior segment OCT, in complementing gonioscopic findings in the management of angle closure glaucoma.
\end{abstract}

Study Design: Descriptive observational case series.

Study Place and Duration: Study was conducted at Eye department of Shifa International Hospital, from January 2019 to March 2019.

Methods: After taking informed consent from the patients, the study was conducted at Shifa International Hospital Islamabad. Patients were selected by convenient sampling technique. Patients were diagnosed on the basis of history and clinical examination. Patients with angle closure on Gonioscopy were included in this series. Detailed ocular examination including visual acuity for distance and near, tonometry, Gonioscopy and anterior segment OCT were performed. Data was collected and presented as case series.

Results: There were 8 patient included in the study with median age of 57 years with $50 \%$ more than 60 years and $50 \%$ less than 60 years of age. Presenting IOP was less than $21 \mathrm{~mm} \mathrm{Hg}$ in $50 \%$ and higher in remaining $50 \%$. On examination $37.5 \%$ were categorized as Primary angle closure suspects (PACS), $12.5 \%$ having Primary angle closure (PAC) and $50 \%$ as primary angle closure glaucoma (PACG). After definitive treatment $12.5 \%$ still needed medical treatment to prevent progression in PACG and none in PACS and PAC.

Conclusion: In narrow angle disease, treatment is designed not only to control intraocular pressure (IOP) but also to keep angle open as much as possible. Appositional closure or peripheral anterior synechiae (PAS) can damage the trabecluar meshwork. Iridoplasty, peripheral Iridotomy (PI) and early lens extraction can defer the need for filtration procedure if done well in time.

Key Words: OCT anterior segment, Narrow angle, Optic nerve head.

How to Cite this Article: Farooq S, Muid J. Role of Anterior Segment OCT in the Management of Primary Narrow Angle Disease. Pak J Ophthalmol. 2020; 36 (4): 348-354.

Doi: https://doi.org/10.36351/pjo.v36i4.1039

\section{INTRODUCTION}

It is estimated that Asians account for over half of Primary open angle glaucoma (POAG) patients worldwide and more than three quarters of those with

Correspondence: Javeria Muid

Ophthalmology Clinic, Shifa International Hospital H-8/4, Islamabad

Email: javeriamuid90@gmail.com

Received: April 14, 2020

Accepted: July 25, 2020
Primary Angle Closure Glaucoma (PACG). The higher rate of glaucomatous optic neuropathy in Asians is probably attributed to PACG. ${ }^{1}$ In a regional population-based study, up to $36 \%$ of POAG and $70 \%$ of PACG patients were blind at the time of presentation. Out of 1.7 million blind people in China, PACG is responsible for the vast majority (91\%) of these cases. ${ }^{2,3}$ PACG is diagnosed by the presence of irido-trabecular contact(ITC) on gonioscopy, contact of $180^{\circ}$ or more is considered as sufficient to be labelled as PAC. One out of four patients of Primary Angle Closure Suspect (PACS) will progress to IOP 
elevation and Peripheral Anterior Synechiae (PAS) in 05 years. $^{4}$ Second stage is PAC, $180^{\circ}$ or more of ITC and IOP elevation or PAS not secondary to any ocular cause. Finally, it is labeled as PACG in the presence of ITC with glaucomatous optic neuropathy.

A population-based study from South India reported 22\% progression of PACS to PAC and 29\% of PAC to PACG over five years. A study of Mongolian population, of people with central anterior chamber (AC) depth of less than $2.53 \mathrm{~mm}$ the incidence of PACS is reported to be $20.4 \%$ over 06 years.

Understanding the pathogenesis of PAC is crucial for management. Most common underlying mechanism is pupil block increasing the differential pressure between posterior and anterior chamber. It causes convex iris with peripheral ITC. Studies demonstrate that darker (thicker) irides may predispose to pupil block. ${ }^{5}$

Anteriorly positioned lens, choroidal expansion due to changes in arterial and venous pressure, blood volume and loose zonules all contribute to development of PAC via anterior lens shift. ${ }^{6}$ Angle crowding is another mechanism due to anteriorly positioned ciliary body compressing the iris root forward against trabecular meshwork. Thirty percent of PACS were diagnosed with plateau iris on ultrasound biomicroscopy (UBM) after laser Iridotomy. ${ }^{7}$ Some eyes may have deep central Anterior Chamber (AC) but have sharp posterior turn at iris root on gonioscopy.

Gonioscopy with four mirror lenses with $9 \mathrm{~mm}$ contact area can help visualize all four angles quickly without the use of coupling agent. It also differentiates appositional from synechial angle closure hence helps in deciding management plan.

OCT of anterior segment has made it possible to objectively analyze angle, AC depth, lens vault and PAS, all possible risk factors towards PACG development. Anterior chamber angle was the best predictable parameter for narrow angle disease and the south Asian studies concludes the same. ${ }^{8}$ Hence, OCT proves to be an important non-contact device to detect and follow narrow angle glaucoma cases with limitation of less penetration through pigment epithelium and poor resolution of inferior quadrants. ${ }^{9,10,11}$ With gonioscopy still being the gold standard, OCT is more sensitive adjunct to screen narrow angles with future risks of angle closure ${ }^{(12)}$ and helps in patient education as well. ${ }^{12,13}$

This case series is presented to find out various mechanisms which are causing the angle closure in our population and to discuss management in each case in a tertiary care setting of Pakistan and the role of anterior segment swept source OCT in management of such cases.

\section{METHODS}

After taking informed consent from the patients, the study was conducted at Shifa International Hospital Islamabad. Patients were selected by convenient sampling technique. Patients were diagnosed on the basis of history and clinical examination. Patients with angle closure on Gonioscopy were included in this series. Detailed ocular examination including visual acuity for distance and near, tonometry, Gonioscopy and anterior segment OCT were performed. Data was collected and presented as case series.

\section{Patient 1}

A 41 years old female with occasional symptom of ocular pain and redness came for evaluation. She was not using any treatment for glaucoma. Her bestcorrected visual acuity (BCVA) was $6 / 6$ in both eyes (BE). Her central corneal thickness (CCT) was within normal range in both eyes with IOP of $16 \mathrm{mmHg}$ in both eyes. She had cup/disc ratio (C/D) of 0.3 bilaterally. Gonioscopy and OCT angle showed narrow angles (non-synechial) in either eye. Laser iridoplasty with PI was done in both eyes one by one and OCT Angle was repeated which showed open angles.

\section{Patient 2}

A 65 years old lady on her routine examination was found to have very narrow angles in BE on slit lamp examination. Her BCVA was $6 / 6(+2.75$ DS) in the right eye $(\mathrm{RE})$ and $6 / 9(+3.0 /-0.50 \times 10)$ in the left eye (LE). She had early cataracts and C/D of 0.5 in BE. Her CCT was $543 \mu \mathrm{m}$ in the RE and $534 \mu \mathrm{m}$ in LE. IOP were $14 \mathrm{mmHg}$ in BE. Her gonioscopy was performed which showed ITC in either eye but open on indentation. OCT RNFL did not show any thinning and OCT angle showed irido-trabecular contact. Her early Phaco with IOL were performed in BE. Her 
angles were wide open on gonioscopy post operatively.

\section{Patient 3}

A 70 years old man was diagnosed as nanophthalmos and prominent lens vault. OCT showed synechial angle closure in left eye, IOP was $42 \mathrm{mmHg}$ and $\mathrm{CD}$ ratio was 0.6. He was managed by Phacotrabeculectomy. He had IOP $28 \mathrm{mmHg}$, narrow angle and CD 0.2 in Rt eye, where phacoemulsification alone resulted in deepening of anterior chamber and angle and control of IOP.

\section{Patient 4}

A 66 years old female came with complaints of blurred vision in $\mathrm{BE}$ for few months. Examination showed cataract in BE with BCVA of 6/15 in RE and 6/9 in LE. IOP was $19 \mathrm{mmHg}$ in $\mathrm{RE}$ and $21 \mathrm{mmHg}$ in LE. On gonioscopy angles were crowded with higher iris root insertion in $\mathrm{BE}$ and $\mathrm{C} / \mathrm{D}$ were normal. She underwent bilateral Phacoemulsification with IOL implant. She was 6/6 (unaided) post-operatively, angles widened and well controlled IOP in BE.

\section{Patient 5}

A 43 years old female presented for glaucoma assessment. She was $6 / 9$ with $0.5 \mathrm{DS}$ in BE. She was using dorzolamide, latanoprost, and timolol in BE. On gonioscopy she had narrow angles in $\mathrm{BE}$ which were open on indentation in one quadrant only. Her IOP were $22 \mathrm{mmHg}$ with C/D of 0.9 and $16 \mathrm{mmHg}$ with $\mathrm{C} / \mathrm{D}$ ratio of 0.6 in $\mathrm{LE}$ and $\mathrm{RE}$ respectively. Slit lamp examination showed early cataracts in either eye. Her OCT optic nerve head showed severe thinning in all the four quadrants in RE and early disc damage in LE. She underwent phaco-trabeculectomy with $0.02 \%$ mitomycin $\mathrm{C}$ in $\mathrm{BE}$ after which her IOP were controlled without anti-glaucoma treatment till the last follow-up.

\section{Patient 6}

A 40 years old male came for glaucoma checkup. He was diagnosed with glaucoma three years back and was using Latanoprost, Dorzolamide, Timolol and Brimonidine. His IOP were $20 \mathrm{mmHg}$ in either eye and had C/D ratio of 0.8 in RE and 0.7 in LE. Gonioscopy showed narrow angles opening on indentation with peripheral iris hump. OCT of angles showed angle of less than $15^{\circ}$ in all quadrants in BE. OCT Optic nerve head showed very early damage. His laser trabeculoplasty (SLT) combined with Iridoplasty was done in both eyes. OCT angle was repeated which showed significantly opened angles in BE and his IOP were well controlled after SLT.

\section{Patient 7}

A 59 years old male presented for glaucoma checkup. His BCVA was 6/9 with narrow angles on gonioscopic examination bilaterally and C/D ratio of 0.7 in $\mathrm{RE}$ and 0.4 in LE plus bilateral NS++. OCT showed ganglion cell and RNFL loss in right eye and normal LE. He had PACG in RE with open angle on indentation and PAC in LE. His IOP was $28 \mathrm{mmHg}$ in RE and 25 $\mathrm{mmHg}$ in LE. His Phacoemulsification with lens implant was done in RE followed by LE (Figure 1). His pressures were under control without any further topical glaucoma treatment and he is on follow-up every 6 months.

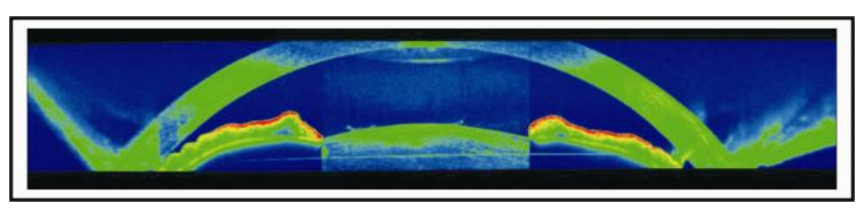

Fig. 1a: Before Cataract Surgery.

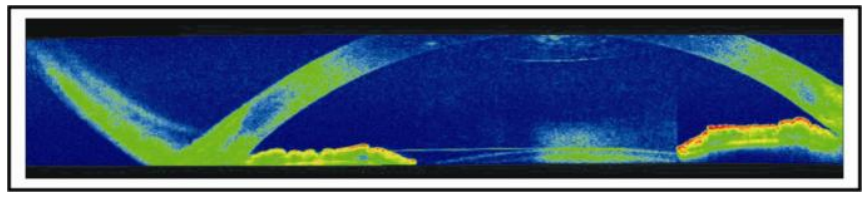

Fig. 1b: After Cataract Surgery.

\section{Patient 8}

A 69 years old female presented for routine eye examination. Her BCVA was 6/6 (+3.0DS) with normal slit lamp examination, normal IOP and C/D ratio of 0.3 bilaterally. Her gonioscopy revealed narrow angles but open on indentation. OCT angle showed angle of less than $15^{\circ}$ and thicker iris (Figure 2a) with no ganglion cell or RNFL loss on OCT glaucoma analysis. Her bilateral $360^{\circ}$ Iridoplasty was done and OCT anterior segment was repeated which showed great improvement in angle appearance (Figure 2b). She is on 03 monthly follow-up and doing perfectly fine with no symptoms or signs of progression to glaucoma so far. 


\section{RESULTS}

There were 8 patients in total out of whom 5 were females and 3 were males. The median age of the patients was 57 years with $50 \%$ of them being more than 60 years and 50\% less than 60 years of age. Presenting IOP was less than $21 \mathrm{mmHg}$ in $50 \%$ and higher in remaining 50\%. On examination, $37.5 \%$ were categorized as PACS, $12.5 \%$ as PAC and $50 \%$ as PACG. After definitive treatment, $12.5 \%$ still needed medical treatment to prevent progression in PACG and none of them required treatment to stop progression to PACS and PAC. The detailed results are summarized in table 1.

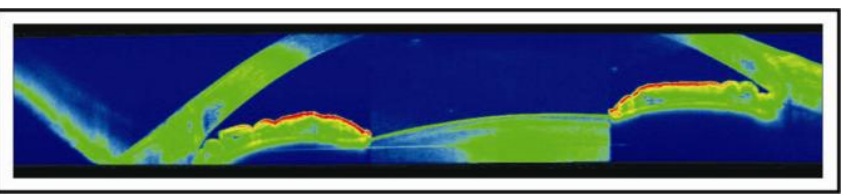

Fig. 2a: Before Iridoplasty Thick Iris with Crowded Angles.

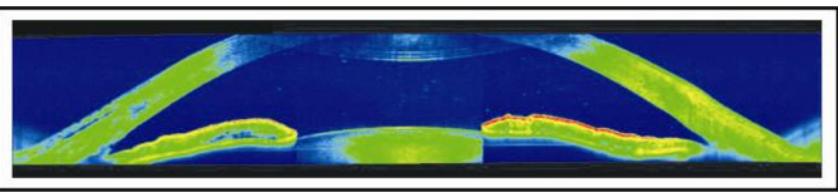

Fig. 2b: After Iridoplasty Showing Deep Angle with Flat Iris Hump.

Table 1: Results According to Age, Sex, Type of Intervention, Outcome and Post-treatment IOP.

\begin{tabular}{|c|c|c|c|c|c|c|}
\hline Age & Sex & $\begin{array}{l}\text { Symptoms at } \\
\text { Presentation }\end{array}$ & $\begin{array}{l}\text { Initial IOP } \\
\text { mmHg }\end{array}$ & Interventions & Outcome & $\begin{array}{l}\text { Medications after } \\
\text { Intervention }\end{array}$ \\
\hline 41 & $\mathrm{~F}$ & Pain and redness & 16 (Both eyes) & PI and Laser Iridoplasty & $\begin{array}{l}\text { Open angle normal } \\
\text { IOP }\end{array}$ & Nil \\
\hline 65 & $\mathrm{~F}$ & No & 22 (Both eyes) & Phacoemulsification with IOL & $\begin{array}{l}\text { Open angle Normal } \\
\text { IOP }\end{array}$ & Nil \\
\hline 70 & M & Blurring and Redness & $\begin{array}{l}28 \mathrm{Rt} \\
42 \mathrm{Lt}\end{array}$ & $\begin{array}{l}\text { Phacoemulsification with IOL } \\
\text { Phacoemulsification with } \\
\text { trabeculectomy + IOL }\end{array}$ & $\begin{array}{l}\text { Normal IOP-Rt Eye } \\
2 \text { anti glaucoma in-Lt } \\
\text { Eye }\end{array}$ & $\begin{array}{l}\text { Nil Rt Eye } 2 \text { Anti } \\
\text { glaucoma Lt eye }\end{array}$ \\
\hline 66 & $\mathrm{~F}$ & Blurred vision & $19 \mathrm{Rt} 21 \mathrm{Lt}$ & Phacoemulsification with IOL & $\begin{array}{l}\text { Normal IOP Both } \\
\text { eyes }\end{array}$ & Nil \\
\hline 43 & $\mathrm{~F}$ & $\begin{array}{l}\text { Known Glaucoma on } \\
3 \text { antiglaucoma } \\
\text { treatment }\end{array}$ & $\begin{array}{l}22 \mathrm{Rt} \\
16 \mathrm{Lt}\end{array}$ & $\begin{array}{l}\text { Phacoemulsification with } \\
\text { trabeculectomy with IOL }\end{array}$ & Normal IOP B/L & Nil \\
\hline 40 & M & Glaucoma check up & $\begin{array}{l}20 \mathrm{Rt} \\
20 \mathrm{Lt}\end{array}$ & Iridoplasty and SLT B/L & Normal IOP & Nil \\
\hline 59 & M & Glaucoma check-up & $\begin{array}{l}28 \mathrm{Rt} \\
25 \mathrm{Lt}\end{array}$ & Phacoemulsification with IOL & IOP controlled & Nil \\
\hline 69 & $\mathrm{~F}$ & Routine eye Check-up & $\begin{array}{l}12 \mathrm{Rt} \\
12 \mathrm{Lt}\end{array}$ & Bilateral Iridoplasty & $\begin{array}{l}\text { Open angle on } \\
\text { Gonioscopy }\end{array}$ & Nil \\
\hline
\end{tabular}

Table 2: Number of Patients According to Intervention.

$\begin{array}{cll}\text { S. } & \text { Intervention } & \text { Number of } \\ \text { 1. } & \begin{array}{l}\text { Peripheral Iridotomy with laser } \\ \text { Pridoplasty }\end{array} & \begin{array}{l}\text { 2 eyes of } 1 \\ \text { patient } \\ 2 \text { eyes of } 1\end{array} \\ \text { 2. } & \text { Laser Iridoplasty alone } & \begin{array}{l}\text { patient } \\ 2 \text { eyes of } 1\end{array} \\ \text { 3. } & \begin{array}{l}\text { Selective laser trabecuplasty with } \\ \text { laser Iridoplasty }\end{array} & \begin{array}{l}\text { patient } \\ 6 \text { eyes of } 3 \\ \text { patients }\end{array} \\ \text { 4. } & \begin{array}{l}\text { Phacoemulsification with lens } \\ \text { implant alone }\end{array} & \begin{array}{l}3 \text { eyes of } 2 \\ \text { patients }\end{array} \\ \text { 5. } & \begin{array}{l}\text { Phacoemulsification }+ \\ \text { trabeculectomy with lens implant }\end{array} & \end{array}$

Table 3: Stage of Glaucoma and Number of Patients.

\begin{tabular}{clc}
\hline S. No & Stage of Glaucoma & $\begin{array}{c}\text { Number of } \\
\text { Patients }\end{array}$ \\
\hline 1. & Primary angle closure suspect & 3
\end{tabular}

2. Primary angle closure 1

3. Primary angle closure glaucoma 4

Table 4: Outcome According to Sex and Number of Patients (3 Months Follow-up).

\begin{tabular}{lll}
\hline $\begin{array}{l}\text { S. } \\
\text { No }\end{array}$ & Outcome & $\begin{array}{l}\text { Number of } \\
\text { Patients }\end{array}$ \\
\hline 1. & Open angle on Gonioscopy & 6 patients \\
2. & $\begin{array}{l}\text { Controlled IOP after management } \\
\text { without any medication }\end{array}$ & $\begin{array}{l}\text { patients } \\
\text { eyes of } 8\end{array}$ \\
3. & $\begin{array}{l}\text { Controlled IOP after management with 1 } \\
\text { topical antiglaucoma medication }\end{array}$ & Nil \\
& $\begin{array}{l}\text { Controlled IOP after management with 2 } \\
\text { 4. }\end{array}$ & $\begin{array}{l}\text { 1 eye of } 1 \\
\text { patient }\end{array}$ \\
\hline
\end{tabular}

\section{DISCUSSION}

Once screened, management options for PACS and PAC may vary among individuals due to subjective 
experiences and intentions to treat or observe. Lasers are simple and effective when some intervention is needed as they help to alter the mechanism of angle closure ${ }^{14}$ YAG laser iridotomy helps relieve pupil block, the most common mechanism in angle closure glaucoma. ${ }^{15}$ Eyes with thicker iris, higher iris insertion and thicker lens will still have narrow angle after laser Iridotomy. ${ }^{16}$ Greatest effect of Laser Peripheral Iridotomy is seen in eyes with greatest baseline pupil block. $^{17}$
Laser trabeculoplasty has role in narrow angle as well once angle is opened by laser iridotomy or Iridoplasty. Its efficacy is proved in Laser Glaucoma study, ${ }^{18}$ Early manifest Glaucoma trial ${ }^{19}$ and Advanced glaucoma intervention study. ${ }^{20}$ Laser peripheral Iridoplasty flattens the peripheral hump of iris, widens the angle in all patients with narrow occludable angles after LPI and changes were maintained till 03 months follow-up. Still its efficacy in PAC stays controversial. $^{21}$

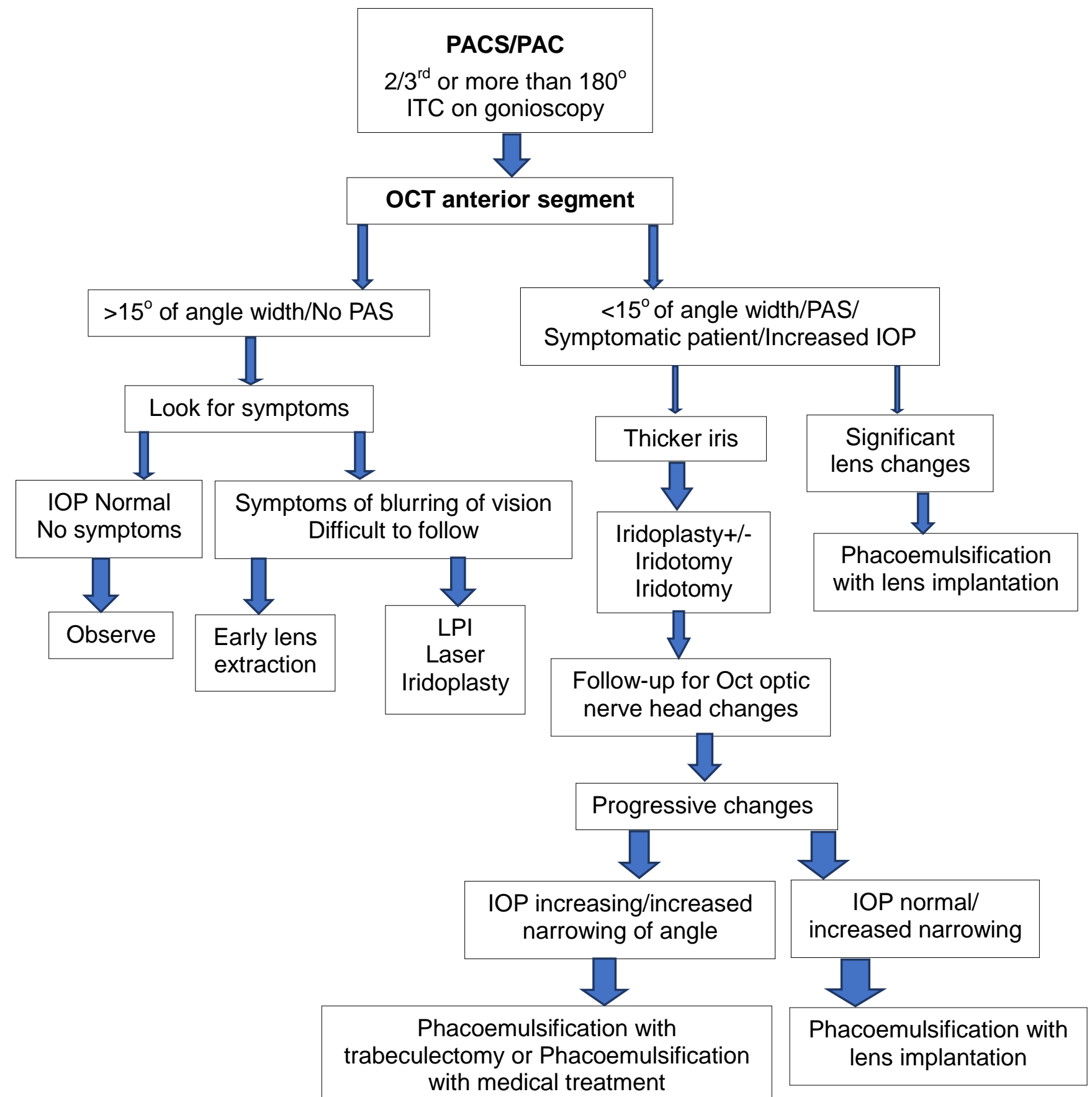


Lens extraction remains an effective treatment in narrow angle disease. In EAGLE study, lens extraction group needed minimal intervention for control of IOP and opening of angle than in laser Iridotomy group. ${ }^{22}$ Once PACG is there Phacoemulsification alone can help if angle is $50 \%$ open on indentation. Phacoemulsification with trabeculectomy in cases with lens changes and $2 / 3^{\text {rd }}$ of the angle is closed and trabeculectomy alone if lens is clear and angle is $2 / 3^{\text {rd }}$ or more closed.

Primary narrow angle disease can present at different stages. Use of new imaging technology has made it easier to have more objective staging of the pathology than ever before. Dr Schumann have found anterior segment OCT, a useful tool in patients with narrow and suspicious angles. With added advantages of being noncontact and can be performed in dark as well. ${ }^{23}$

Medical treatment can help control IOP, which may even worsen the anterior shift of iris lens diaphragm, due to reduced aqueous in AC. Pilocarpine can pull the ciliary body and help to improve the outflow by opening up the trabecular meshwork. It can overcome pupil block and crowding in the plateau iris. Potential side effects are ciliary spasm, miosis and retinal detachment. ${ }^{24}$ Laser peripheral Iridotomy (LPI) bypasses the pupil block and favorably slows the disease progression but some eyes often need further medical treatment or surgical intervention in long term. ${ }^{25}$ Laser peripheral Iridoplasty alone or with LPI mechanically contracts the iris stroma and pulls open the angle. It works best when pupil block is not the main mechanism and may defer the further treatment in PACS and PAC.

Early cataract extraction with minimal lens changes in PAC and PACS has rationale when used specially in cases with increased lens thickness, prominent lens vault and crowding of angle. On an OCT of 62 Chinese patients, prevalence of high IOP and crowding of angle structures was found to be $46.7 \%$ in LPI group as compared to Phacoemulsification group in which prevalence was $3.3 \% .^{26}$

Gonio-synechialysis is performed surgically to strip PAS from trabecular surface. Irreversible damage to meshwork may occur in areas of synechial closure if angle closure exists for longer duration. More aggressive approach towards modifying the angle structures by minimum possible intervention can help prevent millions of people going downhill towards blindness. Being part of a susceptible population, we need to accumulate evidence as we manage patients. Considering this background, following can be logical approach to PAC and PACS patients.

\section{CONCLUSION}

Narrow angle disease presents at different stages and in varied age groups. Patients with permanent adhesion were those who were not diagnosed well in time with gonioscopy and OCT. Anterior segment OCT is a good diagnostic tool in the management of angle closure Glaucoma.

\section{Ethical Approval}

The study was approved by the Institutional review board/Ethical review board.

\section{Conflict of Interest}

Authors declared no conflict of interest.

\section{REFERENCES}

1. Tham YC, Li X, Wong TY, Quigley HA, Aung T, Cheng CY. Global prevalence of glaucoma and projections of glaucoma burden through 2040: a systematic review and meta-analysis. Ophthalmology, 2014; 121 (11): 2081-2090.

2. Baasanhu J, Johnson GJ, Burendei G, Minassian DC. Prevalence and causes of blindness and visual impairment in Mongolia: a survey of populations aged 40 years and older. Bulletin of the World Health Organization, 1994; 72 (5): 771.

3. Foster PJ, Johnson GJ. Glaucoma in China: how big is the problem? $\mathrm{Br}$ J Ophthalmol. 2001; 85 (11): 12771282.

4. Radhakrishnan S, Chen PP, Junk AK, NouriMahdavi K, Chen TC. Laser peripheral iridotomy in primary angle closure: a report by the American Academy of Ophthalmology. Ophthalmology, 2018; 125 (7): 1110-1120.

5. Wyatt H, Ghosh J. Behaviour of an iris model and the pupil block hypothesis. Br J Ophthalmol. 1970; 54 (3): 177.

6. Tarongoy P, Ho CL, Walton DS. Angle-closure glaucoma: the role of the lens in the pathogenesis, prevention, and treatment. Surv Ophthalmol. 2009; 54 (2): 211-225. 
7. Kumar RS, Baskaran M, Chew PT, Friedman DS, Handa S, Lavanya R, et al. Prevalence of plateau iris in primary angle closure suspects: an ultrasound biomicroscopy study. Ophthalmology, 2008; 115 (3): 430-434.

8. Dabasia PL, Edgar DF, Murdoch IE, Lawrenson JG. Noncontact screening methods for the detection of narrow anterior chamber angles. Invest Ophthalmol Vis Sci. 2015; 56 (6): 3929-3935.

9. Li H, Leung CK, Cheung CY, Wong L, Pang CP, Weinreb RN, Lam DS. Repeatability and reproducibility of anterior chamber angle measurement with anterior segment optical coherence tomography. Br J Ophthalmol. 2007; 91 (11): 1490-1492.

10. Maslin JS, Barkana Y, Dorairaj SK. Anterior segment imaging in glaucoma: an updated review. In J Ophthalmol. 2015; 63 (8): 630.

11. Sakata LM, Lavanya R, Friedman DS, Aung HT, Gao H, Kumar RS, Foster PJ, Aung T. Comparison of gonioscopy and anterior segment ocular coherence tomography in detecting angle closure in different quadrants of the anterior chamber angle. Ophthalmology. 2008; 115 (5): 769-774.

12. Baskaran M, Iyer JV, Narayanaswamy AK, He Y, Sakata LM, Wu R, et al. Anterior segment imaging predicts incident gonioscopic angle closure. Ophthalmology, 2001; 122 (12): 2380-2384.

13. Kochupurakal RT, Srikanth K, Jha KN, Rajalakshmi AR, Nagarajan S, Ezhumalai G. Role of optical coherence tomography in assessing anterior chamber angles. J clin Diagn Res. 2016; 10 (4): NC18.

14. Kumar H, Mansoori T, Warjri GB, Somarajan BI, Bandil S, Gupta V. Lasers in glaucoma. Ind J Ophthalmol. 2018; 66 (11): 1539.

15. Nolan WP, Foster PJ, Devereux JG, Uranchimeg D, Johnson GJ, Baasanhu J. YAG laser iridotomy treatment for primary angle closure in east Asian eyes. Br J Ophthalmol. 2000; 84 (11): 1255-1259.

16. Sihota R, Rishi K, Srinivasan G, Gupta V, Dada T, Singh K. Functional evaluation of an iridotomy in primary angle closure eyes. Graefe's Arch Clin Exp Ophthalmol. 2016; 254 (6): 1141-1149.

17. Zebardast N, Kavitha S, Krishnamurthy $\mathbf{P}$, Friedman DS, Nongpiur ME, Aung T, et al. Changes in anterior segment morphology and predictors of angle widening after laser iridotomy in South Indian eyes. Ophthalmology, 2016; 123 (12): 2519-2526.
18. Glaucoma Laser Trial Research Group. The Glaucoma Laser Trial (GLT) and glaucoma laser trial follow-up study: 7. Results. Am J Ophthalmol. 1995; 120 (6): 718-731.

19. Heijl A, Peters D, Leske MC, Bengtsson B. Effects of argon laser trabeculoplasty in the Early Manifest Glaucoma Trial. Am J Ophthalmol. 2011; 152 (5): 842848.

20. Schimiti RB, Abe RY, Tavares CM, Vasconcellos JP, Costa VP. Intraocular pressure control after implantation of an Ahmed glaucoma valve in eyes with a failed trabeculectomy. J Curr Glauc Prac. 2016; 10 (3): 97.

21. Bourne RR, Zhekov I, Pardhan S. Temporal ocular coherence tomography-measured changes in anterior chamber angle and diurnal intraocular pressure after laser iridoplasty: IMPACT study. Br J Ophthalmol. 2017; 101 (7): 886-891.

22. Azuara-Blanco A, Burr J, Ramsay C, Cooper D, Foster PJ, Friedman DS, et al. EAGLE Study Group. Effectiveness of early lens extraction for the treatment of primary angle-closure glaucoma (EAGLE): a randomised controlled trial. The Lancet, 2016; 388 (10052): 1389-1397.

23. Kent C. Making the Most of Anterior Segment OCTThe detailed images produced by this technology are proving to be of value in many clinical situations. Rev Ophthalmol. 2011; 18 (4): 39.

24. Aung T, Ang LP, Chan SP, Chew PT. Acute primary angle-closure: long-term intraocular pressure outcome in Asian eyes. Am J Ophthalmol. 2001; 131 (1): 7-12.

25. Lee JR, Choi JY, Kim YD, Choi J. Laser peripheral iridotomy with iridoplasty in primary angle closure suspect: anterior chamber analysis by pentacam. Kor J Ophthalmol. 2011; 25 (4): 252-256.

\section{Authors' Designation and Contribution}

Sadia Farooq; Consultant Ophthalmologist: Primary surgeon of the patients, Wrote the introduction, discussion, tables and results, Approved the final version.

Javeria Muid; Post Graduate trainee: Wrote the details of cases, Helped with discussion, tables, results and references and Approved the final version.

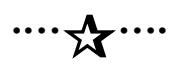

